\title{
Impact of Geometry Effects on Artery Stent Deployment Characteristics
}

\author{
Hashim V, Resmi S L, Dileep P N, Jesna Mohammed, Rajeev A
}

\begin{abstract}
Intravascular stenting is the leading treatment procedure for atherosclerotic coronary heart diseases. Among the various procedures, it is simpler and faster with a high initial success rate. Stent design, stent material, and clinical procedure decide the efficacy and life of stents. Strut thickness and crown radius are two essential design parameters that dictate expansion characteristics of stents. This research work discusses computational analysis of a specific stent, to explore the influence of thickness of strut on the deployment characteristics like stress/strain, foreshortening, recoil, and dog boning. The optimum stent design is one which gives maximum expansion with minimum stress distribution, dogboning, and elastic recoil. Five similar stent models with thickness ranges from $65 \mu$ to $105 \mu$ were modeled and computational method was adopted to simulate the transitory expansion nature of stent/balloon system. The FE results were substantiated with an in-vitro experiment. It was found that strut thickness has a major impact on stent recoil and low impact on foreshortening and dogboning. Foreshortening per unit expansion was almost same for entire models. Strut thickness $70 \mu$ to $80 \mu$ gives better expansion characteristics for the model under study.
\end{abstract}

Keywords: Coronary stent, Expansion characteristics, Finite Element Analysis (FEA), Stress/strain, Strut geometry.

\section{INTRODUCTION}

Congestive heart failure is one of the preeminent sources that leads to casualty of millions of people globally every year. Celluloid or calcified plaque deposition on artery wall creates blockage to blood flow (stenosis) which promote heart attack. Stent implantation is the most prominent and classic therapy for coronary heart diseases. This vascular intervention process is comparatively simple, minimal invasive and fast recovering. After expansion, coronary stents behaves like a perpetual structure and it open the stenosed artery permanently and reinstate blood flow. Placement of stent inside a stenosed artery is a sophisticated process and design

Revised Manuscript Received on December 30, 2019.

* Correspondence Author

Hashim V*, Associate Professor, Dept. of ME, TKM College of Engineering, Kollam, Kerala, India . Email: hashimtkmce@gmail.com

Resmi S L, Assistant Professor, Dept. of ME, TKM College of Engineering . Kollam , Kerala . Email: resmisaji@gmail.com

Dileep P N, Professor, Dept. of ME, TKM College of Engineering . Kollam, Kerala .Email : dileepkollam@yahoo.com

Jesna Mohammed, Assistant Professor, Dept. of ME, TKM College of Engineering . Kollam, Kerala .Email: jesnamohammed@tkmce.ac.in

Rajeev A, Senior Scientist Assistant, Dept. of Medical Devices Engineering, SCTIMST, Trivandrum. Email: rajeev_a@sctimst.ac.in

(c) The Authors. Published by Blue Eyes Intelligence Engineering and Sciences Publication (BEIESP). This is an open access article under the CC BY-NC-ND license (http://creativecommons.org/licenses/by-nc-nd/4.0/) of stent, nature of block and stenting procedure determines the success rate of the patient (Migliavacca et al., 2002). In-stent restenosis is a menace still exists in some of the stented patients. Restenosis was reported around $30-40 \%$ of the total cardiac patients undergone angeoplasty with bare metal stents. More than a hundred variants of stents are available in the market with different geometry and material. The major differentiating factors between the available stents are their geometric design. Ring-type and slotted tube type are two major classifications of stents. Studies proved that ring type design is more efficient in terms of flexibility and radial expansion. The induced stress on artery and hence instent restenosis is less for ring type stent. (S. M. Imani et al., 2015), (Lally et al. (2005). Among all the revascularization procedures angeoplasty leads with $78 \%$ and among the stents, drug eluted stent has got wide acceptance since it gives higher life compared to bare metal stent (Bukala et al., 2016).

Since the physical testing of stent is expensive and incomplete, finite element analysis has got wide acceptance in stent design and analysis. It is one of the reasonable and competitive research tool applied for optimizing the stent characteristics. Finite element method (FEM) was used to expansion characteristics such as recoil (RC), foreshortening (FS) and dog boning (DB) of a slotted tube stent and found that expansion increases with slot length rather than slot width (Chua et al., 2003 and 2004). Schiavone et al. (2017) considered crimped stent in modeling and analysis on expansion to get more realistic results and found that residual stress during crimping at the crown portion will affect the expansion characteristics. In another study by Bedoya et al. (2006), it was identified that the design parameters such as strut spacing, crown radius and axial amplitude has significant influence on normal artery wall mechanism. Over expansion, large strut gap and highly compliant balloon materials creates more contact area and contact stresses on artery and the stent over sizing may lead to high intramural wall stress (Bukala et al., 2016). Another important design parameter is the strut connector and the effect of different shapes of strut connector (' $U$ ', ' $V$ ' and ' $S$ ') on in-stent restenosis was investigated by considering both solid and fluid structural analysis and observed that ' $S$ ' shaped connector has better flexibility and less stress and foreshortening (Qiao et al., 2014). The study by Imani et al. (2013) was more realistic as they considered artery and plaque together with stent and balloon to analyze the probability of restenosis. The design patterns of the stent actually differentiate the performance. Arjun R et al. (2015) identified that, the design pattern influences the expansion and stress distribution. 
The transient expansion behavior of a ring-type stent was investigated by Wang et al. (2006) to study the impact of balloon length on DB. Over length of the balloon will increase DB effect and increase in strut width will reduce DB. Karimi et al.,(2014) investigated the influence of plaque types and stress of stent during implantation without considering the deflation of the balloon.

Finally it can be stated that design optimization is one of the important step to improve the performance of a stent and an attempt to optimize the design parameters of the balloon-expandable MAC stent structure was done by $\mathrm{Li}$, Zhang, \& Ouyang, (2009) using mathematical optimization theory.

From the previous section it is evident that majority of the study on stent deployment was limited to only certain characteristics and the effect of strut thickness on all the characteristics were few and that too by considering only inflation. The effect of strut thickness on all the major expansion characteristics were investigated in this work and the same was substantiated with an in-vitro experiment. The stent/balloon system was expanded with a ramp up pressure load of $912 \mathrm{kPa}$ on the inner surface of the balloon and then it was deflated as done in the experiment to get more realistic results. The geometry of the commercially available bare metal stent Osum 2.75X24 of Meril Life Sciences Pvt. Ltd. has been modeled and FE analysis was performed in
ABAQUS CAE 6.14 static implicit module. The same analysis was repeated on five stent models with variable thickness to identify the influence of strut thickness on deployment characteristics.

\section{METHODOLOGY}

Due to its complicated characteristics, nonlinear behavior and the interaction of individual components, it is difficult and time consuming to perform the analysis on a diseased artery along with stent balloon assembly. Also to get the influence of a parameter relatively on its expansion characteristics, it is not essential to consider the entire complex system. Hence only stent and balloon were considered for this study. Osum 2.75x24, a widely used Indian make bare metal stent of ring-type with 18 rings interconnected with ' $\mathrm{S}$ ' shaped link has been modeled. Each ring consists of a curved strut with a crown. The design dimensions of the stent were extracted with the help of a digital microscope (Leica DVM6) with $12 \mathrm{X}$ to $4740 \mathrm{X}$ magnification and the image of the actual stent was obtained as shown in Fig.1. SOLID WORKS software was depended for generating a solid model of the stent with the dimensions given in Table- I. Model A has been generated with the actual dimensions of the stent (thickness of $0.85 \mathrm{~mm}$ ). (a) Actual stent before expansion

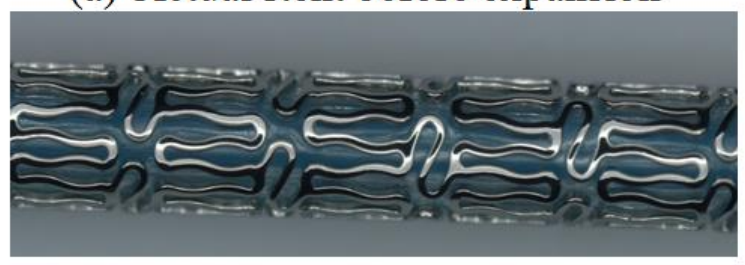

(b) FE model of actual stent

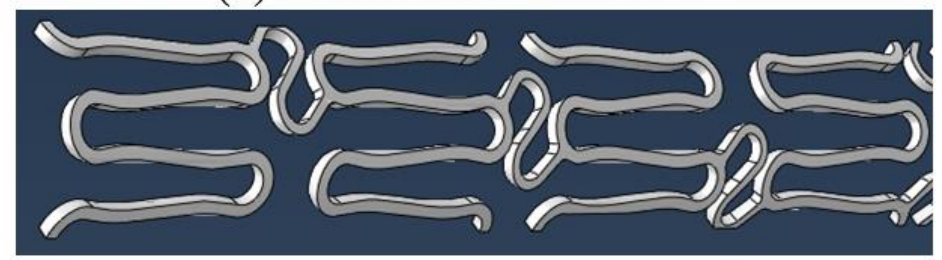

Fig.1. Strut geometry of actual stent and stent model

Table- I: Dimensions of Osum 2.75x24 stent before expansion

\begin{tabular}{ccccccc}
\hline $\begin{array}{c}\text { Name of } \\
\text { the stent }\end{array}$ & $\begin{array}{c}\text { Length } \\
(\mathrm{mm})\end{array}$ & $\begin{array}{c}\text { Inner diameter (un } \\
\text { crimped) }(\mathrm{mm})\end{array}$ & $\begin{array}{c}\text { Strut thickness } \\
(\mathrm{mm})\end{array}$ & $\begin{array}{c}\text { Strut width } \\
(\mathrm{mm})\end{array}$ & $\begin{array}{c}\text { Crown } \\
\text { diameter } \\
(\mathrm{mm})\end{array}$ & $\begin{array}{c}\text { No. of } \\
\text { strut } \\
\text { rings }\end{array}$ \\
\hline Osum & 24 & 1.50 & 0.085 & 0.054 & 0.103 & 18 \\
$2.75 \times 24$ & & & & & & \\
\hline
\end{tabular}

Four different models B, C, D and E were generated with variable strut thickness of $0.065,0.075,0.095$ and $1.050 \mathrm{~mm}$ respectively. The material model of the stent was considered as elasto-plastic and its properties were approximated to Cobalt Chromium L605 as shown in Table- II a (Caoimhe A et.al. 2014). The balloon used for expansion was modeled as cylindrical shape with outer diameter $1.5 \mathrm{~mm}$ and a thickness $0.05 \mathrm{~mm}$. It was $0.03 \mathrm{~mm}$ longer than the stent on either sides. Polyethylene and polyamide are two materials commonly used for balloon. In this case Polyethylene was selected and modeled as hyper elastic non compliant material. It was described by a hyper elastic Mooney-Rivlin strain energy function: $W=C_{10}\left(I_{1}-3\right)+C_{01}\left(I_{2}-3\right)+(J-1)^{2} / D_{1}$. where $I_{1}$ and $I_{2}$ are the first and second stretch invariants, $J$ is the volumetric stretch (or third stretch invariant), $C_{10}, C_{01}$ and $D_{1}$ are model parameters with values given in Table $2 \mathrm{~b}$ (Karimi et.al.,2014).

Table-II a: Material properties of stent

\begin{tabular}{lllll}
\hline $\begin{array}{l}\text { Stent } \\
\text { material }\end{array}$ & $\begin{array}{l}\text { Density } \\
\left(\mathrm{kg} / \mathrm{mm}^{3}\right)\end{array}$ & $\begin{array}{l}\text { Young's } \\
\text { modulus } \\
(\mathrm{GPa})\end{array}$ & $\begin{array}{l}\text { Yield } \\
\text { strength } \\
(\mathrm{MPa})\end{array}$ & $\begin{array}{l}\text { Poisson's } \\
\text { ratio }\end{array}$ \\
\hline $\mathrm{L}-605$ & $9.1 \mathrm{e}^{-6}$ & 243 & 476 & 0.30 \\
\hline & &
\end{tabular}

\& Sciences Publication 
Table-II b: Mooney-Rivlin model parameters for balloon

\begin{tabular}{lllll}
\hline Material & $\begin{array}{l}\text { Density } \\
\left(\mathrm{Kg} / \mathrm{mm}^{3}\right)\end{array}$ & $\mathrm{C}_{10}$ & $\mathrm{C}_{01}$ & $\mathrm{D}_{1}$ \\
\hline Polyurethane & $1.07 \mathrm{e}^{-6}$ & 1.03 & 3.69 & 0 \\
\hline
\end{tabular}

\section{A. FE Analysis}

In the first phase, FE analysis on model A was performed by considering the loading conditions similar to in-vitro experiment. A non-linear static 3D solid model was considered for stent and balloon. Stent balloon assembly was created with frictional contact as shown in Fig.2. An expansion pressure of $912 \mathrm{kPa}$ was applied on the inner surface of the balloon (ramp-up) in step 1 and the balloon was deflated by applying a pressure in the opposite direction in step 2 (ramp-down). The step time for ramp-up and ramp-down were $0.8 \mathrm{~s}$. The kinetic energy was confirmed that it was very small compared to the internal energy throughout the analysis and it was within acceptable limit (Karimi et.al.,2014). Since the simulation involves material, geometry and contact non-linearity the computation time was quite large and hence a quarter of the circumference and half of the length was considered for the analysis. Boundary conditions were selected in such a fashion that in the planes of symmetry, all the nodes perpendicular to the plane of symmetry were arrested. The stent was enabled to move in the axial direction to imbibe shortening of stent during expansion. To permit only radial expansion, the same condition was also assigned for balloon. An automatic surface to surface algorithm approach was opted for the assembly as did for nonlinear contact problems. Mesh compatibility study has been conducted on unit cell and an optimum mesh element size of $0.035 \mathrm{~mm}$ with a curvature control of maximum deviation factor 0.01 was selected.

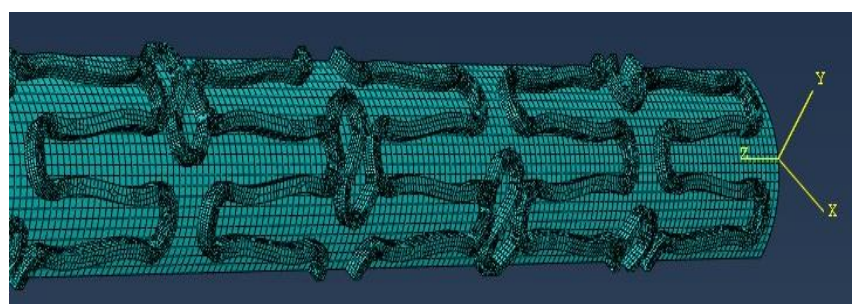

Fig.2. Meshed model of stent balloon assembly

The second phase of the analysis was to study the impact of strut thickness on expansion aspect of stent. For this, computation was repeated on other four models (Model B, C, $\mathrm{D}$ and $\mathrm{E}$ ) with same load, mesh and boundary conditions and the results were compared to study the impact of variation in the thickness on following characteristics.
i. Maximum expansion and Stress
ii. $\mathrm{FS}=\left(L_{1}-L_{2}\right) / L_{1}$
iii. $\mathrm{DB}=\left(R_{2}\right.$ distal $-R_{2}$ central $) / R_{2}$ distal
iv. $\mathrm{RC}=\left(R_{r}-R_{d}\right) / R_{r}$

Where $L_{1}$ and $L_{2}$ are the length of the stent before and after expansion respectively. $R_{2 \text { distal }}$ and $R_{2 \text { central }}$ are the radii of stent at the end and middle after expansion.

$R_{r}$ and $R_{d}$ are the radii in the middle of the stent at ramp up and ramp down respectively

\section{RESULTS AND DISCUSSIONS}

\section{A. Simulation of Model A}

FE analysis of Model A represents the deployment of actual Osum stent. It was obvious that maximum stress and strain were seen in the crown region of strut. During balloon expansion, the ring-shaped strut pull apart and unbends the crown part. Minimum stress was found at the straight portion of the strut since there was no deformation and the cross-section of the strut found unchanged during the expansion (Bedoya et al., 2006). Initially the stent expands slowly from $1.67 \mathrm{~mm}$ to $1.82 \mathrm{~mm}$ in the elastic region as the pressure ramps up from 0 to $500 \mathrm{kPa}$. It transforms to plastic deformation as input pressure exceeds the yield strength of L-605. The stress-strain variation was transient in nature and Fig. 3 gives the stress strain variation at the middle of the stent. Stress increases up to $600 \mathrm{kPa}$ during inflation and it decreases to $60 \mathrm{kPa}$ immediately at the end of deflation due to release of pressure. Similarly, the stent expands to a displacement of $0.689 \mathrm{~mm}$ exponentially and due to elastic recoil, it reduces to $0.604 \mathrm{~mm}$. Fig. 4 shows the stress-strain distribution on the outer surface of the model $\mathrm{A}$ with maximum von Mises stress of $731.5 \mathrm{kPa}$ and displacement of $0.689 \mathrm{~mm}$. Maximum stress of $527 \mathrm{kPa}$ and displacement of $0.604 \mathrm{~mm}$ was observed for the same model at the end of deflation as shown in Fig. 5. Hence the final diameter obtained at the middle was $2.878 \mathrm{~mm}(1.67+2 * 0.604)$, where 1.67 is the initial diameter of the stent before expansion. As the symmetric boundary conditions were imposed on both ends of the stent the free end expands more than the middle and hence DB effect was observed. Similarly a very small reduction in the length (FS) was also noticed after expansion.

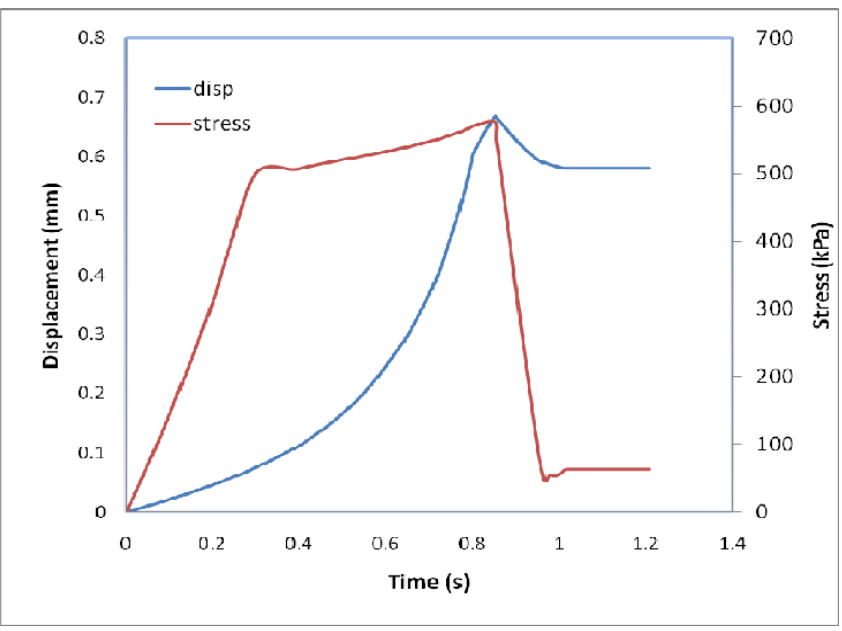

Fig.3. Change in displacement and stress with time 
(a) Maximum stress

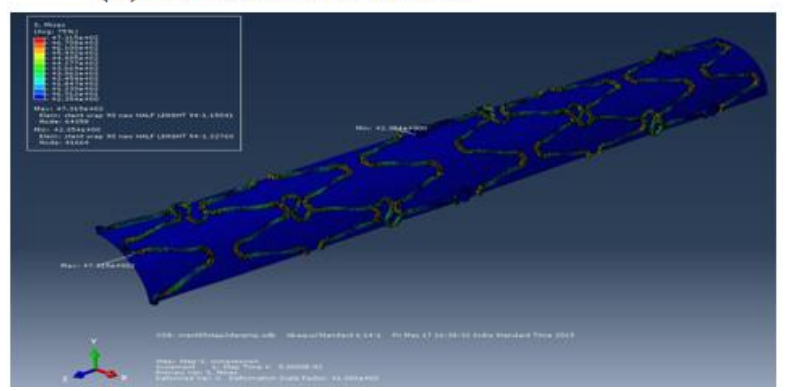

(b) Maximum strain

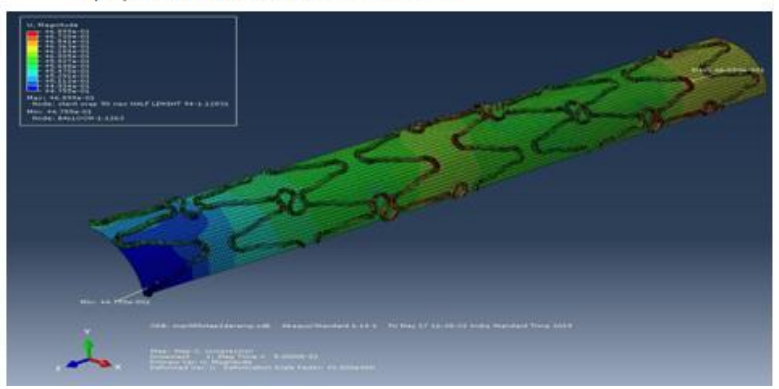

Fig.4. Maximum stress and strain before deflation for Model A

(a)Maximum stress

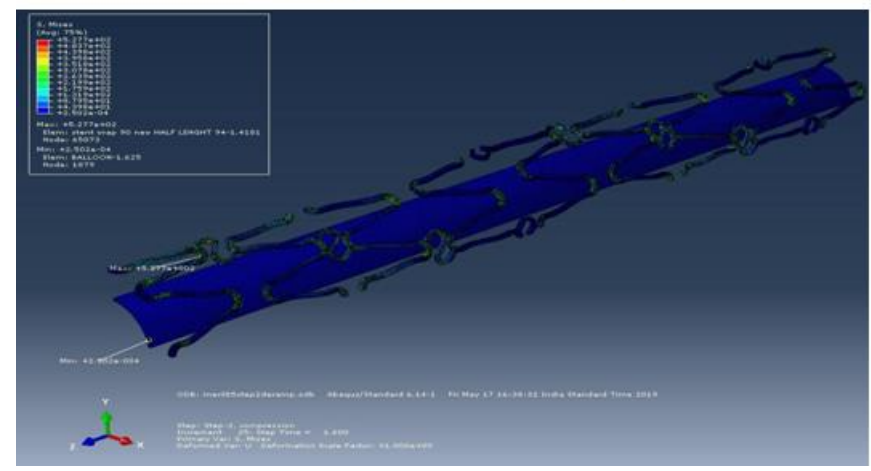

(b)Maximum strain

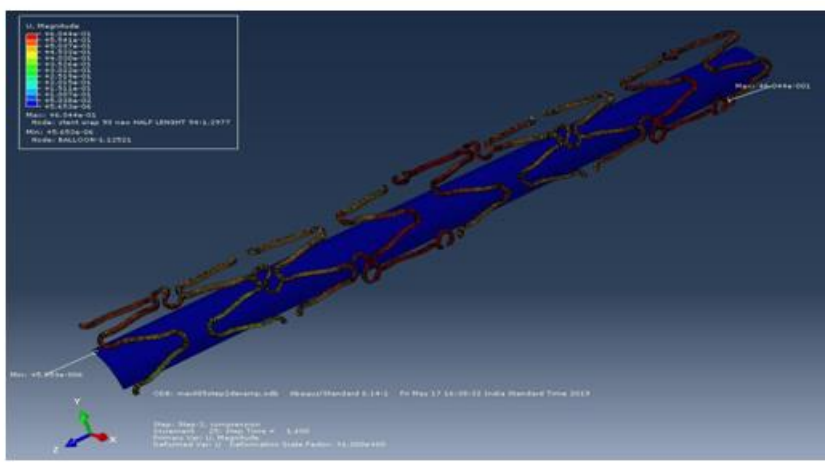

Fig.5. Maximum stress and strain after deflation for Model A

\section{B. Experimental Validation}

An experimental system as shown in Fig. 6 was used for inflating the balloon in a controlled fashion to expand the stent (Sujesh et al., 2010). It consists of a standard pressure controller (GDS Instruments, UK, 3 MPa pressure range), a non-contact type Optical micrometer (LS-7501 controller with LS-7030M measuring head, M/s. Keyence, Japan) and a fixture for holding the stent and delivery system. During pressurization, distilled water from the pressure controller enters through the stent delivery system and inflates the balloon as done in angioplasty and the stent expands. The ramp up pressure was $912 \mathrm{kPa}$ with a slope of $100 \mathrm{~ms} / \mathrm{kPa}$ and was held for 24s (holding time), then the balloon was deflated (ramp down) to atmospheric pressure. Optical micrometer measures the outer diameter of the middle of the stent during expansion on time with an accuracy of $\pm 0.002 \mathrm{~mm}$ and the data was scanned by a PC. The variation of the stent diameter with respect to pressure was recorded and saved in the computer using Lab VIEW virtual instrumentation software.

Fig.7 shows the change in the diameter of the stent with respect to applied pressure both in experiment and computation. The stent expands to $2.962 \mathrm{~mm}$ at ramp up pressure and then reduces to $2.904 \mathrm{~mm}$ due to elastic recoil at ramp down. The maximum diameter obtained in the computation was $3.048 \mathrm{~mm}$ at ramp up and $2.878 \mathrm{~mm}$ at ramp down. The difference in the final diameter of the stent was only less than $1 \%$ which was within the acceptable limit and hence the methodology of analysis was validated.

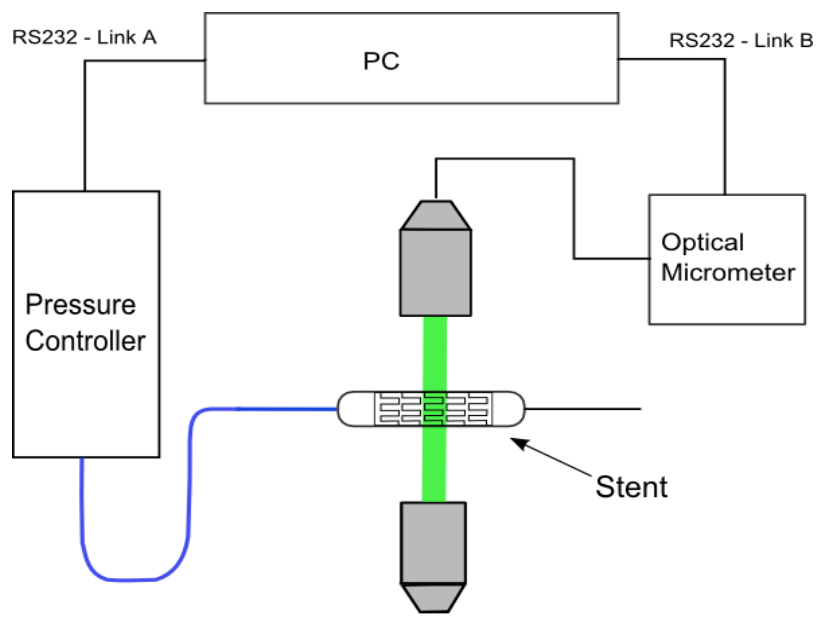

Fig.6. Stent expansion system (experimental setup)

However, the expansion process (strain rate) with respect to applied pressure observed for simulation was quite high in experiment as shown in Fig. 7. In the actual practice the expansion of the stent was quicker during the pressure changes from $200 \mathrm{kPa}$ to $300 \mathrm{kPa}$, and above $300 \mathrm{kPa}$ it changes to slow and steady. But in computation, we did not consider the crimping of stent to simplify the analysis, hence the stent expands gradually with an exponential increment and reaches maximum. But the end result will not be affected by this assumption (Bukala et al., 2016).

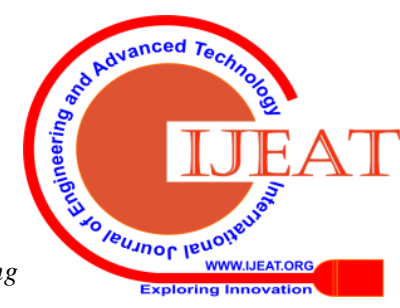




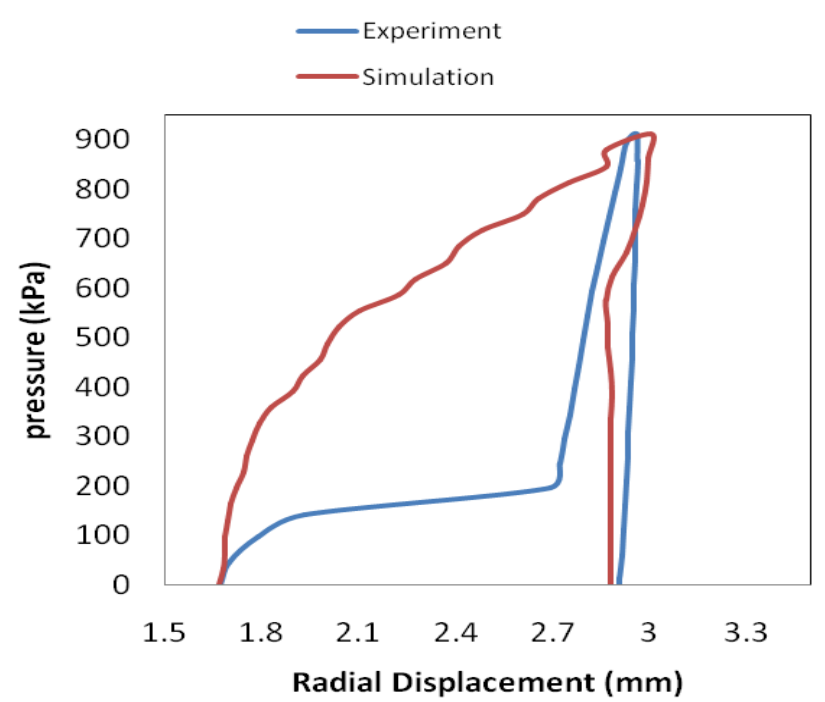

Fig.7. Pressure Vs Displacement from experiment and simulation

\section{Expansion Characteristics of Various Models}

The second phase of the analysis compares the expansion characteristics of five stent models. FS, RC, and DB are the important expansion characteristics. FS of $1.08 \%$ was observed for model A against $2.40 \%$ obtained from experiment. Length of the stent was reduced to $23.42 \mathrm{~mm}$ at the end of expansion as shown in Fig. 8. In the computation result, displacement along different directions were noticed as different with respect to time as shown in Fig. 9., where $\mathrm{Ux}$ and Uy are the radial displacement in $\mathrm{X}$ and $\mathrm{Y}$ directions respectively and $\mathrm{Uz}$ is the axial displacement . It was found that the displacement along axial direction was negligible compared to radial direction. When the diameter of the stent increases, a small decrease in the length (FS) was observed. FS should be minimum to prevent injury on artery wall during deployment. It decreases with the strut thickness because FS is directly proportional to the expansion and nothing to do with the strut thickness. It was proved that the shape of the connector has an important role in controlling the FS. A curved connector can compensate FS by stretching its curve when the stent expands (Wang et al., 2006). Another characteristic observed was shrinking of stent soon after the pressure release due to elastic recoil. RC of $4.09 \%$ was observed for Model A against 5.8\% observed in the experiment. It was found that stent RC increases with strut thickness as shown in Fig. 12. In angeoplasty, it is essential to get exact opening of the artery after stent implantation. Therefore recoil to be kept as minimum as possible or it could be predictable so that allowance can be provided during expansion.

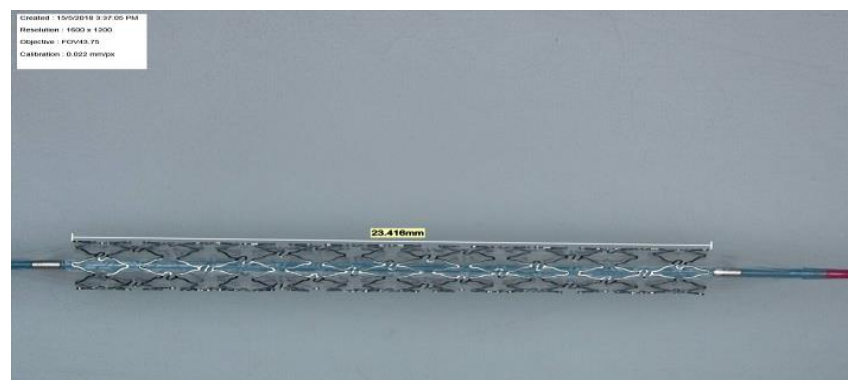

Fig.8. Image of the actual stent after expansion

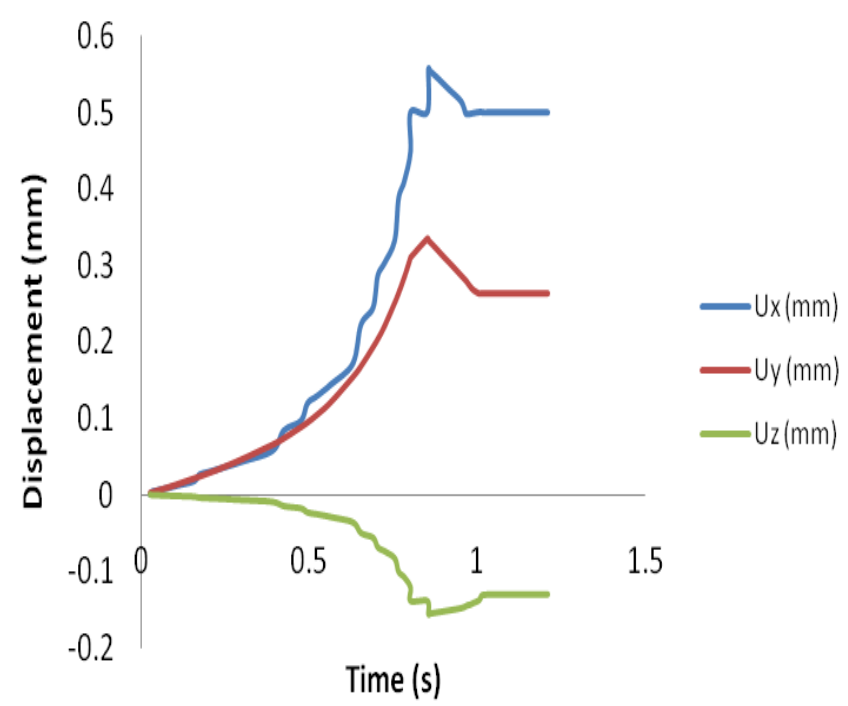

Fig.9. Expansion and recoil of the stent in different direction

Since the over length of the balloon was $0.03 \mathrm{~mm}$, two ends of the stent expand slightly larger than the middle portion which is known as DB effect. 7.23\% of DB was observed in model A which was considerably higher than the actual case. This is due to the changes in length and shape of the balloon model compared to the actual balloon. The balloon model was assumed as plain cylindrical shape but the actual was hemispherical shape on both of its ends. The DB effect decreases initially, then it increases to maximum at strut thickness $0.085 \mathrm{~mm}$ and again decreases. Therefore no specific correlation was observed between strut thickness and DB. It mainly depends on over length of balloon and strut width rather than thickness (Wang et al., 2006). The expansion characteristics of different models were compared and presented in Table- III and the trends of FS, RC and DB with respect to strut thickness were shown in Fig.11. For a given input pressure, the induced stress on an expanded stent is less if the stent expands without much resistance. If so the stent with minimum strut thickness can expand more with low stress. But in this study maximum expansion was found for the Model A (strut thickness of $0.085 \mathrm{~mm}$ ) and minimum stress was found in the Model E (strut thickness $0.105 \mathrm{~mm}$ ). This indicates that not only the strut thickness but also design pattern influences the expansion and stress concentration. Therefore it was always advisable to select the strut thickness as low as possible for a specific pattern. From this study the strut thickness between $0.070 \mathrm{~mm}$ and $0.080 \mathrm{~mm}$ shows better performance when all the characteristics were considered as shown in Fig.12. 


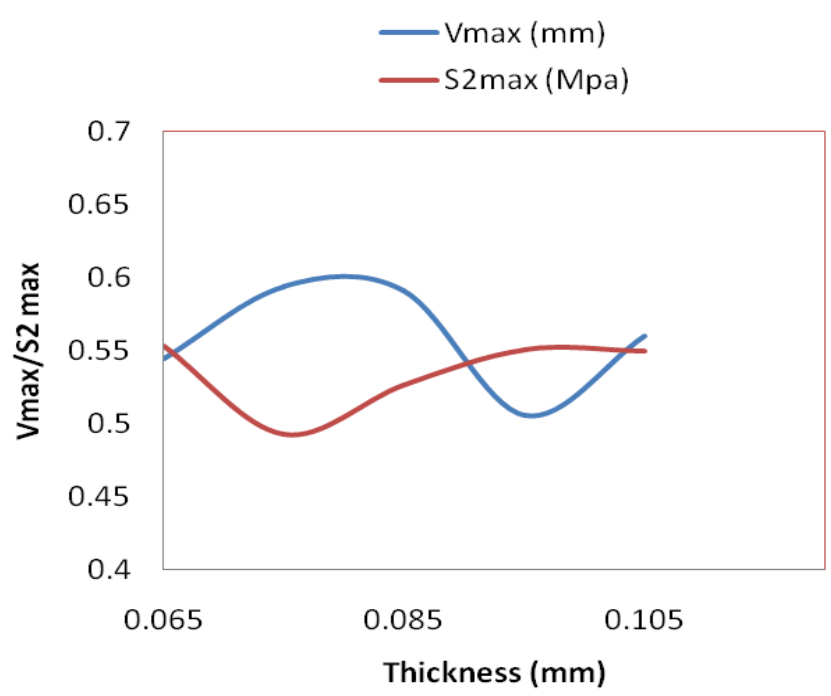

Fig.10. Maximum Stress and Strain in the various models

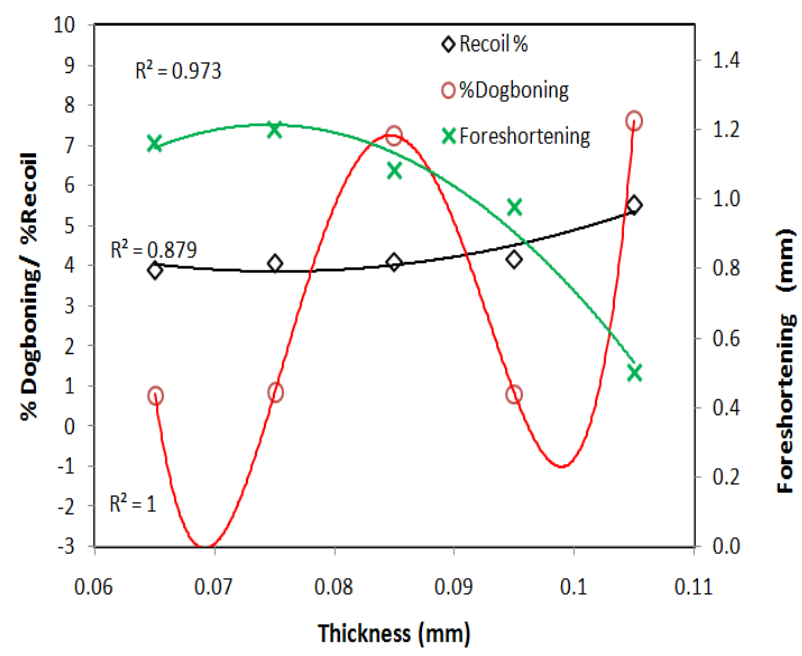

Fig.11. Trends of Recoil, Foreshortening and Dogboning with respect to strut thickness

Table-III: Expansion characteristics of 5 models

\begin{tabular}{|c|c|c|c|c|c|c|c|c|c|c|c|}
\hline \multirow{2}{*}{$\begin{array}{c}\text { Model } \\
\text { (Thickness) } \\
\text { (mm) }\end{array}$} & \multicolumn{4}{|c|}{ AFTER INFLATION OF BALLOON } & \multicolumn{6}{|c|}{ AFTER DEFLATION OF BALLOON } & \multirow[b]{2}{*}{$\begin{array}{l}\mathrm{RC} \\
(\%)\end{array}$} \\
\hline & $\begin{array}{c}\mathrm{S}_{1} \\
\max \\
(\mathrm{kPa})\end{array}$ & $\begin{array}{l}\text { Umax } \\
(\mathrm{mm})\end{array}$ & $\underset{(\mathrm{mm})}{\mathrm{Ux}}$ & $\underset{(\mathrm{mm})}{\mathrm{Uz}}$ & $\begin{array}{c}\mathrm{S}_{2} \\
\max \\
(\mathrm{kPa})\end{array}$ & $\underset{(\mathrm{mm})}{\mathrm{Vmax}}$ & $\frac{\mathrm{Vx}}{(\mathrm{mm})}$ & $\begin{array}{c}\mathrm{Vz} \\
(\mathrm{mm})\end{array}$ & $\begin{array}{l}\text { FS } \\
(\%)\end{array}$ & $\begin{array}{l}\text { DB } \\
(\%)\end{array}$ & \\
\hline $\mathrm{B}(0.065)$ & 681 & 0.610 & 0.591 & -0.179 & 553 & 0.545 & 0.534 & -0.139 & 1.158 & 0.790 & 3.900 \\
\hline $\mathrm{C}(0.075)$ & 697 & 0.653 & 0.642 & -0.190 & 493 & 0.594 & 0.582 & -0.144 & 1.200 & 0.839 & 4.060 \\
\hline $\mathrm{A}(0.085)$ & 732 & 0.689 & 0.557 & -0.156 & 527 & 0.604 & 0.500 & -0.130 & 1.083 & 0.227 & 4.090 \\
\hline $\mathrm{D}(0.095)$ & 700 & 0.564 & 0.553 & -0.156 & 551 & 0.506 & 0.495 & -0.117 & 0.975 & 0.820 & 4.170 \\
\hline $\mathrm{E}(0.105)$ & 672 & 0.619 & 0.528 & -0.073 & 550 & 0.560 & 0.453 & -0.060 & 0.500 & 7.600 & 5.500 \\
\hline
\end{tabular}

$\mathrm{S}_{1} \max$ and $\mathrm{S}_{2} \max$ - Maximum von- Mises stress before and after deflation

Umax and Vmax - Maximum strain at the end of the stent before and after deflation

$\mathrm{Ux}$ and $\mathrm{UZ}$ - Displacement at the middle of the stent in $\mathrm{X}$ and $\mathrm{Z}$ direction before deflation

$\mathrm{Vx}$ and $\mathrm{Vz}$ - Displacement at the middle of the stent in $\mathrm{X}$ and $\mathrm{Z}$ direction after deflation

FS - Percentage of foreshortening after deflation

DB - Percentage of dogboning after deflation

RC - Percentage of recoil of the stent after deflation

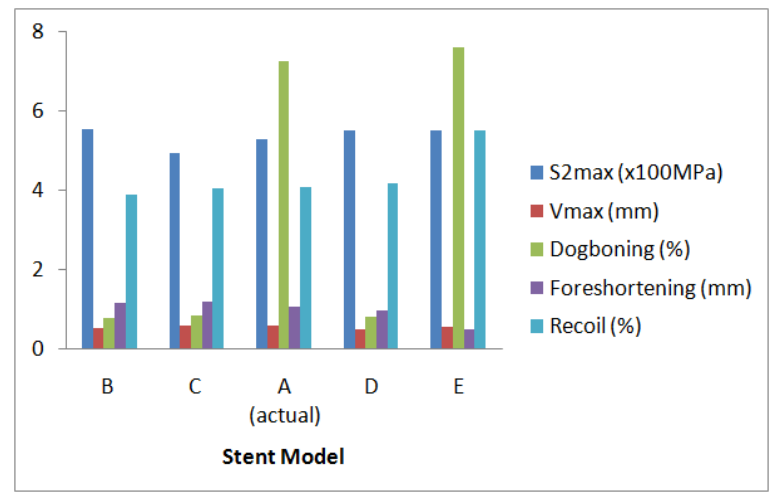

Fig.12. comparison of different stent models

\section{CONCLUSION}

The novelty of this study is that five similar models with a strut thickness ranging from $65 \mu$ to $105 \mu$ were explored to find the impact of strut thickness on all the expansion characteristics simultaneously. The analysis was performed by considering both inflation and deflation of the balloon The results of experiment and simulation were found consistent especially, the expansion and elastic recoil. The crown part of the strut found with maximum stress and strain and little change in the cross-section of the stent throughout the expansion. Among the five models, the model with strut thickness between $70 \mu$ and $80 \mu$ gives better performance with larger expansion, low stress, low dogboning and low recoil. Foreshortening of stent found proportional to its expansion and FS per unit expansion was almost same for all the models and strut thickness has no significant role on dogboning effect. It was identified that elastic recoil of the stent was the only characteristic which directly affect strut thickness. This methodology can be applied for studying the affect of any geometrical parameters on expansion behavior and the results could be applied to optimize the stent design. More accurate results can be expected if patient specific artery is included in this study.

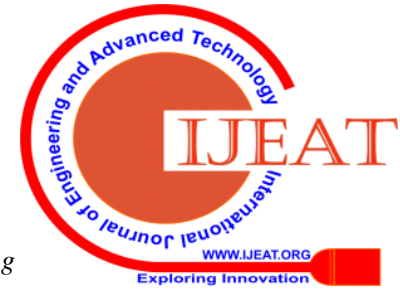




\section{ACKNOWLEDGEMENT}

The authors would like to acknowledge the financial support from Research Seed money Scheme of TEQIP-II, TKM College of Engineering, Kerala, India and the support rendered by the Department of Medical Devices Engineering, Sree Chitra Tirunal Institute for Medical Sciences and Technology Devices Engineering, Trivandrum for conducting the experiment.

\section{REFERENCES}

1. Alireza Karimi, Mahdi Navidbakhsh, Hiroshi Yamada, Reza Razaghi. A non linear finite element simulation of balloon expandable stent for assessment of plaque vulnerability inside a stenotic artery. Medical and Biological Engineering 2014. https://doi.org/ 10.1007/s11517-014-1163-9

2. Arjun R., Hashim V. (2015). Effect of inflating pressure on the expansion behaviour of coronary stent and balloon: A finite element analysis. International Coference on Aerospace and Mechanical Engineering, 14-16 December 2015, TKM College of Engineering, Kollam.

3. Bedoya, J., Services, S. E., Timmins, L., \& Moreno, M. R. (2006) Effects of stent design parameters on normal artery wall mechanics. Journal of Biomechanical https://doi.org/10.1115/1.2246236

Engineering.

Bukala, J., Kwiatkowski, P., \& Malachowski, J. (2016). Numerical analysis of stent expansion process in coronary artery stenosis with the use of non-compliant balloon. Biocybernetics and Biomedical Engineering, 36(1), 145-156. https://doi.org/10.1016/j.bbe.2015.10.009

5. Caoimhe A. Sweeney, Barry O'Brein, Peter E. McHugh, Sean B. Leen experimental characterization for micromechanical modelling of CoCr stent fatigue. Biomaterials, $35 \quad$ (2014) 36-48 http://dx.doi.org/10.1016/j.biomaterials.2013.09.087

6. Chua, S. N. D., Donald, B. J. Mac, \& Hashmi, M. S. J. (2003). Finite element simulation of stent and balloon interaction. Journal of Materials Processing Technology, 144, 591-597. https://doi.org/10.1016/S0924-0136(03)00435-7

7. Chua, S. N. D., Macdonald, B. J., \& Hashmi, M. S. J. (2004). Effects of varying slotted tube ( stent ) geometry on its expansion behaviour using finite element method. Journal of Materials Processin Technology, 156,1764-1771. https://doi.org/10.1016/j.jmatprotec.2004.04.395

8. 8. Imani, M., Moazemi, A., \& Aghili, A. L. (2013). The comprehensive finite element model for stenting: The influence of stent design on the outcome after coronary stent placement. Journal of Theoretical and Applied Mechanics, (January).

9. Imani, S. M., Goudarzi, A. M., Valipour, P., Barzegar, M., Mahdinejad, J., \& Ghasemi, S. E. (2015). Application of finite element method to comparing the NIR stent with the multi-link stent for narrowings in coronary arteries. Acta Mechanica Solida 9166(October https://doi.org/10.1016/S0894-9166(15)30053-7

10. Lally, C., Dolan, F., \& Prendergast, P. J. (2005). Cardiovascular stent design and vessel stresses: a finite element analysis. Journal of Biomechanics, 38 ,

1574-1581. https://doi.org/10.1016/j.jbiomech.2004.07.022

11. Li, N., Zhang, H., \& Ouyang, H. (2009). Shape optimization of coronary artery stent based on a parametric model, 45, 468-475. https:/ /doi.org/10.1016/j.finel.2009.01.001

12. Migliavacca, F., Petrini, L., Colombo, M., Auricchio, F., \& Pietrabissa, R. (2002). Mechanical behavior of coronary stents investigated through the finite element method. Journal of Biomechanics, 35(6), 803-811. https://doi.org/10.1016/S0021-9290(02)00033-7

13. Qiao, A. (2014). Numerical simulation of vertebral artery stenosis treated with different stents. Journal of Biomechanical Engineering, 136(April), 1-9. https://doi.org/10.1115/1.4026229

14. Schiavone, A., Qiu, T.-Y., \& Zhao, L.-G. (2017). Crimping and deployment of metallic and polymeric stents -- finite element modelling. Vessel Plus, 1(1), 12-21. https://doi.org/10.20517/2574-1209.2016.03

15. Sujesh S, Rajeev A, Praveen MS, Bipin G, Rufus R, Muraleedharan CV. An Automated Instrumentation System for Expansion and Deployment Characterization of Tubular Stent Devices. International Conference on System Dynamics and Control -ICSDC 19th -22nd August 2010

16. Wang, W., Liang, D., Yang, D., \& Qi, M. (2006). Analysis of the transient expansion behavior and design optimization of coronary stents by finite element method. Journal of Biomechanics 39, 39, 21-32. https://doi.org/10.1016/j.jbiomech.2004.11.003

\section{AUTHORS PROFILE}

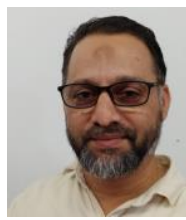

Hashim V, is working as Associate Professor in the Department of Mechanical Engineering of TKM College of Engineering, Kerala, India. Masters in Manufacturing Technology from National Institute of Technology, Calicut. He undergoes Doctor studies in the area of Biomechanics. He is guiding many under-graduate and post-graduate projects in the institute. He has completed a research project funded by AICTE and has published 4 journal papers and has presented research articles in international conferences.

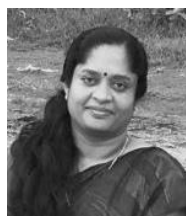

Resmi S L, is working as Assistant Professor in the Department of Mechanical Engineering at Thangal Kunju Musaliar College of Engineering ,Kerala,India.She is guiding many under-graduate and post-graduate projects in the institute.With Masters in Refrigeration and Cryogenic Engineering, she is pursuing her Doctoral Studies at Kerala University.She has many national and international publication to her cred

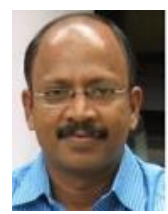

Dileep PN, is working as Professor in the Department Mechanical Engineering of TKM College of Engineering since 1991. His research interest is in Fractute Mechanics and Biomechanics. He has completed a research project under Research Project Scheme of All India Council for Technical Education. Three research scholars persuing Doctor studies under his guidence and has more than 10 research publications in reputed journals and conferences.

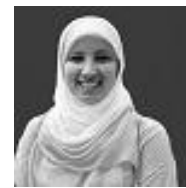

Jesna Mohammed, is working as Assistant Professor in the Department of Mechanical Engineering at Thangal Kunju Musaliar College of Engineering, Kerala, India. She is guiding many under-graduate and post-graduate projects in the institute. With Masters in Energy Engineering, she is pursuing her Doctoral Studies at Kerala University. She has 4 international publications to

her credit.

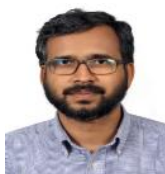

Rajeev A, is working as Senior Scientist Assistant in the Department of Medical Devices Engineering in the Biomedical Technology Wing of Sree Chitra Tirunal Institute for Medical Science and Technology, Trivandrum. He has completed M-Tech in Process Control and Instrumentation from National Institute of Technology, Tiruchirappalli. He has many research papers in his account.

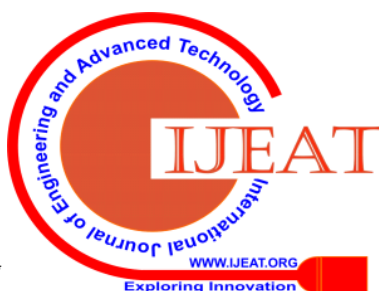

